East African Medical Journal Vol. 77 No. 4 April 2000

PREDICTORS OF CD4+ LYMPHOCYTE COUNT AMONG HIV-SEROPOSITIVE AND HIV-SERONEGATIVE PREGNANT WOMEN IN DAR ES SALAAM, TANZANIA

S. H. Kapiga, M.D., Sc.D., Department of Epidemiology and Biostatistics, D. Mwakagile, M.D., MMed., Department of Microbiology and Immunology, Muhimbili University College of Health Sciences, Dar es Salaam, Tanzania, D. Spiegelman, Sc.D., Department of Epidemiology and Biostatistics, Havard School of Public Health, Boston, USA, G. I. Msamanga, M.D., Sc.D., Department of Community Health, Muhimbili University College of Health Sciences, D. Hunter, MBBS, Sc.D., Department of Epidemiology, W. W. Fawzi, MBBS, Dr.PH., Department of Nutrition, Harvard School of Public Health, Boston, Massachusetts, USA.

Request for reprints to: Dr. S. H. Kapiga, Department of Epidemiology and Biostatistics, Muhimbili University College of Health Sciences, P.O. Box 65015, Dar es Salaam, Tanzania.

\title{
PREDICTORS OF CD4+ LYMPHOCYTE COUNT AMONG HIV-SEROPOSITIVE AND HIV- SERONEGATIVE PREGNANT WOMEN IN DAR ES SALAAM, TANZANIA
}

\author{
S. H. KAPIGA, D. MWAKAGILE, D. SPIEGELMAN, G. I. MSAMANGA, D. HUNTER and W. W. FAWZI
}

\begin{abstract}
Objective: To determine the predictors of CD4+ lymphocyte count among pregnant women in Dar es Salaam, Tanzania.

Methods: Between 04/1995 and 03/1997, HIV-seropositive $(n=1,027)$ and HIV- seronegative $(\mathrm{n}=\mathbf{2 8 0})$ pregnant women were interviewed to obtain socio-demographic characteristics. Later, blood samples was collected for determination of T-lymphocyte subsets and other haematological indices.

Results: CD4+ lymphocyte count was significantly higher among HIV-seronegative women ( mean $=770$ cells $/ \mathrm{mm}^{3}$, standard deviation $(\mathrm{SD})=232$ cells $/ \mathrm{mm}^{3}$ ) than $\mathrm{HIV}$-seropositive women (mean=422 cells $/ \mathrm{mm}^{3}, \mathrm{SD}=\mathbf{2 0 5}$ cells $/ \mathrm{mm}^{3}$ ). Most $\mathrm{HIV}$-seropositive women were asymptomatic, in WHO clinical stage $1(84.3 \%)$. Among HIV-seropositive women, total white blood count (WBC) and erythrocyte sedimentation rate (ESR) remained significantly correlated with CD4+ after adjusting for other predictors in multivariate analyses. For women of average age 25 years, the CD4+ lymphocyte count increased by about 16 cells $/ \mathrm{mm}^{3}$ for each increment of $1000 \mathrm{WBC}$ cells $/ \mathrm{mm}^{3}$, while each $10 \mathrm{~mm} / \mathrm{hr}$ increase in ESR was associated with a reduction of CD4+ lymphocyte count of about 8 cells $/ \mathrm{mm}^{3}$.

Conclusion: These results show that simple and inexpensive haematological indices cannot be recommended for use as alternative measures of HIV-related immunosuppression in this population of mainly asymptomatic women.
\end{abstract}

\section{INTRODUCTION}

The T-lymphocyte cell surface glycoprotein cluster determinant 4 (CD4) has been studied extensively because it is the major receptor for HIV(1). Repeated or persistent exposure of the immune system to viral antigen leads to general impairment of functional capability of immune competent cells, immune system dysfunction and an abnormal programme of cell death(2). Consequently, there is progressive reduction in the number of $\mathrm{CD} 4+$ lymphocytes in HIV-infected individuals.

Although the CD4+ lymphocyte count provides important prognostic information, determination of lymphocyte subsets requires resources and technical expertise not routinely available in most developing countries. This is particularly true in most sub-Saharan African countries where approximately $67 \%$ of the world's HIV-infected population reside(3). In these countries, affordable alternative markers of immunosuppression in HIV-infected patients would be valuable. Such markers would improve the ability of health care workers to monitor disease progression and help in clinical staging of HIV disease. Total lymphocyte count has been found to be highly correlated with CD4+ lymphocyte count(4), and has been shown to be a prognostic indicator of both short-term and long-term survival $(5,6)$. As a result, the WHO advocates the use of total lymphocyte count as an alternative to CD4+ lymphocyte count when the latter is not available(7). Other simple blood indices, such as low red blood cell count, low haematocrit or haemoglobin, and elevated erythrocyte sedimentation rate (ESR) have been identified to be predictors of decreasing CD4+ lymphocyte counts(8-11).

Other studies have evaluated the role of potential cofactors for progression to AIDS or AIDS-related complex among HIV-infected persons. These factors include sociodemographic characteristics such as age(11), cigarette smoking(12,13), and dietary intake of key nutrients(1416). The majority of these studies were conducted in developed countries and may not be generalisable to developing countries. Hence, there is a critical need for data from less developed countries, such as Tanzania, where more than 1.5 million people are estimated to have 
been infected by the HIV(17). Furthermore, there is limited data to show the association between potential co-factors and CD4+ lymphocyte count among pregnant women. Thus, we studied predictors of CD4+ Iymphocyte count among HIV-seropositive and HIV-seronegative pregnant women in Dar es Salaam Tanzania, and assessed the association between CD4+ lymphocyte count and clinical stages of HIV/AIDS disease. We also examined samples from comparable HIV-seronegative women to describe the distribution of T-lymphocyte subsets among healthy pregnant women in the study population.

\section{MATERIALS AND METHODS}

Recruitment and study procedures: Data used in this report were collected from HIV-seronegative pregnant women receiving antenatal care in Dar es Salaam, Tanzania. HIV-seropositive women were participating in an ongoing randomised, controlled, double-blind clinical trial designed to assess the effect of supplementation of vitamins on perinatal transmission of HIV and progression of HIV disease. HIV-seronegative women were participating, as controls, in a sub-study aimed at assessing the psycho-social impact of HIV-seropositivity among women enrolled in the trial. Recruitment of HIV-seropositive women was done between April 1995 and March 1997 at four main antenatal clinics serving the three administrative districts of Dar es Salaam city. During the study period, all pregnant women between 12-27 weeks of gestation receiving antenatal care at selected clinics received a brief description of the study procedures and HIV pre-test counseling. Blood for HIV testing was collected from women who gave verbal consent $(n=13,867)$. All women were requested to return to the clinics within one to two weeks for HIV post-test counselling. Out of 1,802 women who were HIV-seropositive, 1,085 (60\%) returned for their results and consented to participate in the trial. Two hundred and eighty HIV-seronegative women were sampled from women who returned for HIV results at one of the clinics (Mwananyamala) and consented to be followed in the psycho-social sub-study.

After enrollment, all HIV-seropositive women were transferred to the study clinic at Muhimbili Medical Centre (MMC) where they were randomised and followed up to the time of delivery and for at least two years thereafter. Similar follow up was done among HIV-seronegative women at the Mwananyamala clinic. Standard antenatal and postnatal care and counseling were provided during the follow up period. At baseline, all women were interviewed by trained female nurses using standardised questionnaires to obtain information about sociodemographic characteristics, complete birth histories, sexual practices, and contraceptive use histories.

After interview, blood was collected in EDTA vacutainer tubes and transported to the laboratory within three to four hours for determination of T-lymphocyte subsets. Among HIVseropositive women, other haematological indices were estimated from the blood samples. To assess within-person variability of CD4+ lymphocyte measurements, we collected duplicate blood samples from 79 women. To ensure that technicians who conducted the tests could not identify which samples were from the same woman, the second sample of blood from each woman was labeled using a different serial number and presented to the laboratory with other samples. The study protocol was approved by the Ethical Committee of Tanzania National AIDS Control Programme, Research and Publications Committee of Muhimbili University College of Health Sciences, and the Institutional Review Board of the Harvard School of Public Health.
Laboratory methods: Blood for HIV testing and Tlymphocyte subsets was processed in the Department of Microbiology and Immunology at MMC. HIV infection was diagnosed using an enzyme linked immunosorbent assay (ELISA) (Murex Biotech Ltd, Dartford, UK) and reactive samples were confirmed by Western blot (Bio-Rad Laboratories Ltd, Hertfordshire, UK) according to the World Health Organisation (WHO) criteria(18). The FACScount system (Becton Dickinson Systems San Jose, CA) was used for enumeration of the Tlymphocyte subsets. Unlysed whole blood was mixed, reverse pipetted and run on the FACScount instrument and analysed according to the manufacturer's recommendation to obtain absolute counts of CD3+, CD4+ and CD8+ lymphocytes. Blood samples rejected by the FACScount system were analysed by using the FACScan cytometer (Becton Dickinson Immunocytometry Systems, San Jose, CA). The percentages of CD3+, CD4+ and CD8+ lymphocytes obtained from flow cytometry were multiplied by total Iymphocyte count measured on whole blood within six hours of collection on a Microdiff 18 Coulter cell counter (Coulter Corporation, Miami, FL) to obtain absolute counts of CD3+, CD4+ and CD8+ lymphocytes. Both FACScount and FACScan were serviced regularly by the manufacturers.

Estimation of haemoglobin and total white blood cells (WBC) was done by using the CBC5 Coulter counter (Coulter Corporation, Miami, FL) while WBC differential count was done manually. ESR was estimated by mixing 750 microlitres of blood with 250 microlitres of $3.8 \%$ disodium citrate in the ESR tube. The tube was left to stand upright at $90^{\circ}$ for one hour and the results reported in $\mathrm{mm} /$ hour. For haematocrit, capillary tubes loaded with blood were sealed at one end with wax and centrifuged in a haematocrit centrifuge at $5000 \mathrm{rpm}$ for 15 minutes. Later, packed cell volume was read on a hematocrit scale and reported as percentages. Vitamin A and E serum levels were determined by using high performance liquid chromatography procedures.

Statistical methods: These analyses included the 1029/ $1085(94.8 \%)$ HIV-seropositive women and 280 HIVseronegative women with baseline CD4+ lymphocyte measurements. Two HIV-seropositive women with CD4+ lymphocyte count $>1700$ cells $/ \mathrm{mm}^{3}$ were excluded from the analyses. All analyses were performed using SAS statistical software (SAS Institute Inc., Cary, NC, USA). The frequency distributions of CD4+ lymphocyte count and of all potential predictors was initially inspected and extreme data values checked. The maximum likelihood estimates of between- and withinperson variances in the underlying CD4+ lymphocyte count were obtained from a random effects model as implemented by SAS PROC MIXED(19). The intraclass correlation coefficient (ICC) of reliability was obtained by dividing the between-person variance by the sum of the between- and within-person variances. The $95 \%$ confidence intervals for the ICC was calculated as given by Hankinson et al (20). The coefficient of variation of $\mathrm{CD} 4+$ lymphocyte count is the ratio of the within-person standard deviation of the loge CD4+ lymphocyte count, to the sample mean loge CD4+ lymphocyte count.

The distribution of continuous variables among HIVseropositive and HIV-seronegative women was compared by using the Wilcoxon rank-sum test(21). Age-adjusted Spearman's partial correlation coefficients $\left(r_{S}\right)$ were used to quantify the associations between pairs of continuous variables. Later, multiple linear regression models were fitted to determine haematological indices which were significant predictors of CD4+ lymphocyte count among HIV-seropositive women. After identifying the final model, the distribution of the residuals was inspected and 
tested for normality. Since residuals from all models were not normal, robust variance estimates were used in all the results presented. This method gives standard errors for the regression coefficients that are asymptotically unbiased even if the normality assumption is violated(19).

Further analyses were done to determine the ability of haematological indices in the final model to predict CD4+ count. Initially, predicted CD4+ lymphocyte count for each subject was calculated from the final regression model equation obtained when the index subject was excluded from the dataset. To assess the validity of the regression model for predicting CD4+ lymphocyte count in future patients, a jacknifed correlation between the observed and predicted CD4+ counts was calculated(22). Later, CD4+ count was categorised into two groups $\left(<200\right.$ cells $/ \mathrm{mm}^{3}$ and $>200$ cells $\left./ \mathrm{mm}^{3}\right)$ and we tested the ability of logistic regression models to identify women with CD4+ counts $<200$ cells $/ \mathrm{mm}^{3}$. Using probabilities of CD4+ count $\leq 200$ cells $/ \mathrm{mm}^{3}$ predicted by the models, we calculated the sensitivity and specificity of predicting CD4+ count $<200$ cells $/ \mathrm{mm}^{3}$ at various cut-off points of predicted probabilities. The receiver operating characteristic (ROC) curve was used to determine the cut-off point which maximises both sensitivity and specificity(23), and the area under the ROC curve was used to calculate the accuracy of the models.

\section{RESULTS}

The distribution of baseline socio-demographic characteristics, HIV clinical stages, haematological indices and serum nutrients in the study population are presented in Table 1 . The CD4+ lymphocyte count was significantly higher among HIV-seronegative (mean $=770$ cells $/ \mathrm{mm}^{3}$, standard deviation $(\mathrm{SD})=232$ cells $/ \mathrm{mm}^{3}$ ) than HIVseropositive women (mean $=422$ cells $/ \mathrm{mm}^{3}, \mathrm{SD}=205$ cells/ $\mathrm{mm}^{3}$ ). Only $131(12.8 \%)$ of HIV-seropositive women and none of the HIV-seronegative women had CD4+ lymphocyte count below 200 cells $/ \mathrm{mm}^{3}$. HIV-seronegative women had significantly higher CD3+ lymphocyte count than HIV-seropositive women. However, CD8+ lymphocyte count was significantly higher among HIVseropositives $\left(\right.$ mean $=748$ cells $/ \mathrm{mm}^{3}, \mathrm{SD}=330$ cells $\left./ \mathrm{mm}^{3}\right)$ than among HIV-seronegatives $\left(\right.$ mean $=498$ cells $/ \mathrm{mm}^{3}$, $\mathrm{SD}=211$ cells $/ \mathrm{mm}^{3}$ ). HIV-seropositive women were significantly older than HIV-seronegative women. Most HIV-seropositive women were asymptomatic, in WHO clinical stage 1 (84.3\%). CD4+ lymphocyte count decreased significantly with advancing clinical stage of the disease. Baseline serum vitamin $\mathrm{A}$ and $\mathrm{E}$ results were available from 365/1085 (33.6\%) HIV-seropositive women. Mean serum vitamins $\mathrm{A}$ and $\mathrm{E}$ was $25.9 \mu \mathrm{g} / \mathrm{dl}(\mathrm{SD}=10.0 \mu \mathrm{g} / \mathrm{dl})$ and $9.4 \mu \mathrm{mol} / \mathrm{L}(\mathrm{SD}=2.4 \mu \mathrm{mol} / \mathrm{L})$ respectively.

Table 1

Distribution of socio-demograpbie characteristics, haematological indices and serum nutrients among HIV-seropositive and HIV-seronegative women, Dar es Salaam, Tanzania

\begin{tabular}{|c|c|c|c|c|c|}
\hline Variable & $\begin{array}{l}\text { HIV-positive } \\
(\mathrm{n}=1027) \\
\text { Mean }\left(\mathrm{SD}^{\mathrm{b}}\right)\end{array}$ & $\begin{array}{l}\text { HIV-negative } \\
(n=280) \\
\text { Median }\end{array}$ & $\operatorname{Mean}\left(\mathrm{SD}^{\mathrm{b}}\right)$ & Median & P-value ${ }^{a}$ \\
\hline \multicolumn{6}{|c|}{ Socio-demographic and anthropometric variables } \\
\hline Age(years) & $25(5)$ & 24 & $23(5)$ & 21 & 0.0001 \\
\hline Gestation age at recruitment (weeks) & $18(3)$ & 18 & $19(3)$ & 19 & 0.002 \\
\hline Weight (kg) & $57(9)$ & 56 & $56(9)$ & 55 & 0.01 \\
\hline Height $(\mathrm{cm})$ & $156(6)$ & 155 & $155(7)$ & 155 & 0.51 \\
\hline Mid-upper arm circumference $(\mathrm{cm})$ & $23(3)$ & 23 & $25(3)$ & 25 & 0.04 \\
\hline Body mass index $\left(\mathrm{kg} / \mathrm{m}^{2}\right)$ & $24(3)$ & 23 & $23(3)$ & 23 & 0.01 \\
\hline \multicolumn{6}{|l|}{ Hematological indices and serum nutrients } \\
\hline CD $4+$ count $\left(\right.$ cells $\left./ \mathrm{mm}^{3}\right)$ & $422(205)$ & 405 & $770(232)$ & 715 & 0.0001 \\
\hline \multicolumn{6}{|c|}{ CD $4+$ count $\left(\right.$ cells $/ \mathrm{mm}^{3}$ ) by HIV clinical stages ${ }^{\mathrm{c}}$} \\
\hline HIV Stage 1 & $428(204)$ & 410 & & & \\
\hline HIV Stage 2 & $394(207)$ & 363 & & & \\
\hline HIV Stage 3 & $326(226)$ & 270 & & & \\
\hline CD8+ count $\left(\right.$ cells $\left./ \mathrm{mm}^{3}\right)$ & $748(330)$ & 680 & $498(211)$ & 470 & 0.0001 \\
\hline CD3+ count $\left(\right.$ cells $\left./ \mathrm{mm}^{3}\right)$ & $1230(451)$ & 1177 & $1339(406)$ & 1293 & 0.0004 \\
\hline Total white blood cell count (cells $/ \mathrm{mm}^{3}$ ) & $5240(2336)$ & 4600 & & & \\
\hline Total Iymphocyte count (cells $/ \mathrm{mm}^{3}$ ) & $1886(931)$ & 1701 & & & \\
\hline Haemoglobin $(\mathrm{g} / 100 \mathrm{ml})$ & $10(2)$ & 10 & & & \\
\hline Erythrocyte sedimentation rate $(\mathrm{mm} / \mathrm{hr})$ & $59(36)$ & 50 & & & \\
\hline Haematocrit(\%) & $29(5)$ & 29 & & & \\
\hline Serum vitamin $A(\mu \mathrm{g} / \mathrm{dl})^{\mathrm{d}}$ & $26(10)$ & 25 & & & \\
\hline Serum vitamin $E(\mu \mathrm{mol} / \mathrm{L})^{\mathrm{d}}$ & $9(2)$ & 9 & & & \\
\hline
\end{tabular}

${ }^{\mathrm{a}}$ Wilcoxon rank-sum test; ${ }^{\mathrm{b}}$ SD denotes standard deviation, ${ }^{\mathrm{c}}$ Based on WHO HIV clinical staging; ${ }^{\mathrm{d}}$ Serum measurements of these nutrients were available from 365 HIV-seropositive women only. 
Table 2

Age-adjusted Spearman's correlation coefficients $\left(r_{S}\right)$ between CD4+ lymphocyte count and socio-demographic variables, haematological indices and serum nutrients among HIV-seropositive and HIV-seronegative women, Dar es Salaam, Tanzania

\begin{tabular}{|c|c|c|c|c|}
\hline \multirow[t]{2}{*}{ Predictor } & \multicolumn{2}{|c|}{ HIV-positive (N=1027) } & \multicolumn{2}{|c|}{ HIV-negative (N=280) } \\
\hline & $\mathrm{r}_{\mathrm{S}}$ & P-value & $\mathrm{r}_{\mathrm{S}}$ & P-value \\
\hline \multicolumn{5}{|c|}{ Socio-demographic/anthropometric variables } \\
\hline Age (years) & -0.20 & 0.0001 & -0.09 & 0.15 \\
\hline Gestation age at recruitment (weeks) & 0.001 & 0.98 & 0.07 & 0.26 \\
\hline Weight (kg) & 0.03 & 0.33 & 0.07 & 0.22 \\
\hline Height (cm) & -0.01 & 0.79 & -0.04 & 0.51 \\
\hline Mid-upper arm circumference (cm) & 0.08 & 0.01 & 0.05 & 0.43 \\
\hline Body mass index (kg/m2) & 0.05 & 0.13 & 0.11 & 0.07 \\
\hline \multicolumn{5}{|l|}{ Haematological indices/serum nutrients } \\
\hline $\mathrm{CD} 8+$ count $\left(\right.$ cells $\left./ \mathrm{mm}^{3}\right)$ & 0.28 & 0.0001 & 0.53 & 0.0001 \\
\hline $\mathrm{CD} 3+$ count $\left(\right.$ cells $\left./ \mathrm{mm}^{3}\right)$ & 0.66 & 0.0001 & 0.87 & 0.0001 \\
\hline Total Iymphocyte count (cells/mm3) & 0.18 & 0.0001 & & \\
\hline Haemoglobin level (g/100ml) & 0.10 & 0.001 & & \\
\hline Haematocrit (\%) & 0.10 & 0.001 & & \\
\hline Total white blood cells (cells/mm³) & 0.22 & 0.0001 & & \\
\hline Erythrocyte sedimentation rate $(\mathrm{mm} / \mathrm{hr})$ & -0.17 & 0.0001 & & \\
\hline Serum vitamin $\mathrm{A}(\mu \mathrm{g} / \mathrm{dl})^{*}$ & 0.08 & 0.12 & & \\
\hline Serum vitamin $\mathrm{E}(\mu \mathrm{mol} / \mathrm{L})^{*}$ & 0.08 & 0.14 & & \\
\hline
\end{tabular}

* Serum measurements of these nutrients were available from 365 HIV-seropositive women only.

The CD4+ lymphocyte count reliability coefficient was $0.77(95 \%$ confidence interval $(\mathrm{CI})=0.67-0.85)$ and the coefficient of variation $(\mathrm{CV})$ was $24 \%(95 \% \mathrm{CI}=20$ $29 \%$ ). Table 2 shows age-adjusted correlations between CD4+ lymphocyte count and continuous predictors among HIV-seropositive and HIV-seronegative women. Of all socio-demographic and anthropometric variables presented, age had the strongest correlation with CD4+ lymphocyte count among HIV-seropositive women $\left(\mathrm{r}_{\mathrm{S}}=\right.$ $-0.20, \mathrm{p}=0.0001)$. Mid-upper arm circumference had a weak but significant positive correlation with CD4+ lymphocyte count among HIV-seropositive women $\left(\mathrm{r}_{\mathrm{S}}=\right.$ $0.08, \mathrm{p}=0.01$ ). Among HIV-seronegative women, none of the socio-demographic and anthropometric variables were significantly associated with CD4+ lymphocyte count. All other T-lymphocyte subsets and haematological indices measured in this study were significantly correlated with CD4+ lymphocyte count among HIV-seropositive women. The strongest association was observed between CD4+ lymphocyte count with $\mathrm{CD} 3+\left(\mathrm{r}_{\mathrm{S}}=0.66, \mathrm{p}=0.0001\right)$, $\mathrm{CD} 8+\left(\mathrm{r}_{\mathrm{S}}=0.28, \mathrm{p}=0.0001\right)$ lymphocyte counts, and total white blood cell count $\left(\mathrm{r}_{\mathrm{S}}=0.22, \mathrm{p}=0.0001\right)$. Similarly, $\mathrm{CD} 3+\left(\mathrm{r}_{\mathrm{S}}=0.87, \mathrm{p}=0.0001\right)$ and $\mathrm{CD} 8+\left(\mathrm{r}_{\mathrm{S}}=0.53, \mathrm{p}=\right.$ $0.0001)$ lymphocyte count were significantly correlated with CD4+ lymphocyte count among HIV-seronegative women. Baseline serum vitamins $\mathrm{A}$ and $\mathrm{E}$ were not correlated with CD4+ lymphocyte count among HIVseropositive women.

Results from multiple linear regression models are presented in Table 3. As shown in Model 1, total WBC and ESR were the only haematological indices that were significantly correlated with CD4+ lymphocyte count in
Table 3

Predictors of CD4+ T-lymphocyte count - results from multiple linear regression models

\begin{tabular}{llllr}
\hline & \multicolumn{2}{c}{ Model 1 } & \multicolumn{2}{c}{ Model 2 } \\
\cline { 2 - 5 } & $\beta$ & P value* & $\beta$ & P value* $^{*}$ \\
\hline $\begin{array}{l}\text { Intercept } \\
\begin{array}{l}\text { Total white blood cell } \\
\text { count (per 1000 cells/mm }\end{array}\end{array}$ & 392.5 & 389.6 & & \\
$\begin{array}{l}\text { Erythrocyte sedimentation } \\
\text { rate (per 10 mm/hr) } \\
\text { Age (years)** }\end{array}$ & 15.9 & 0.0001 & 15.2 & 0.0001 \\
Model R & -7.7 & 0.0001 & -7.1 & 0.0001 \\
& & & -7.1 & 0.0001 \\
\hline
\end{tabular}

* All p-values are based on robust variance estimates.

** Age was centered around its mean value of 25 years.

the final model after adjusting for other determinants. Among women of average age, the CD4+ lymphocyte count increased by about 16 cells $/ \mathrm{mm}^{3}$ for each increment of $1000 \mathrm{WBC}$ cells $/ \mathrm{mm}^{3}$, while each $10 \mathrm{~mm} / \mathrm{hr}$ increasein ESR was associated with a reduction of CD4+ Iymphocyte count of about 8 cells $/ \mathrm{mm}^{3}$. The jacknifed correlation between observed CD4+ lymphocyte count and counts predicted from this model was 0.23 . These results were not significantly changed after adding age in the model (model 2). However, these models explained less than $10 \%$ of the CD4+ lymphocyte count variance in this population. Among HIV-seronegative women, none of the socio-demographic and anthropometric variables 
were significantly correlated with CD4+ lymphocyte count in multivariate analyses.

The sensitivity and specificity of predicting CD4+ lymphocyte count below 200 cells $/ \mathrm{mm}^{3}$ using model probabilities at various cut-off points was calculated by using the ROC curve. The proportion of the area of the entire graph that lies beneath the curve was 0.63 . The sensitivity and specificity was maximised when the models predicted probabilities was greater than 0.127 . If all patients with this predicted probabilities were classified as having CD4+ lymphocyte counts below 200 cells $/ \mathrm{mm}^{3}$, the sensitivity and specificity of this procedure was $60 \%$ and $64 \%$ respectively. Increasing the probability cut-off point was associated with increasing sensitivity and decreasing specificity.

\section{DISCUSSION}

The reliability of CD4+ lymphocyte measurements was high indicating that laboratory error was not a major source of misclassification in this study. The distribution of T-lymphocyte subsets among healthy HIV-seronegative pregnant women were similar to those reported by other studies in both developing and industrialised countries (mean 736 - 828 cells $/ \mathrm{mm}^{3}$ )(24-26). Several studies have observed a reduction in CD4+ lymphocyte count during pregnancy among HIV-seropositive women(24-27) and a return to normal levels at time of delivery $(25,27)$ or during the first few weeks after delivery $(24,26)$. Potential mechanisms to explain these changes include pregnancy induced leukocytosis that leads to increased WBC count and decreased percentage of lymphocytes(28), haemodilution resulting from increased blood volume(24), re-distribution of $\mathrm{CD} 4+$ cells in tissues and lymph nodes(27), and hormonal changes associated with pregnancy(29). These changes complicate the interpretation of T-lymphocyte subset results in studies involving pregnant women. The findings of this study provide information about the distribution of T-lymphocyte subsets among both HIV-seropositive and HIVseronegative pregnant women. The results from healthy HIV-seronegative women provide an important source of information which can be used as reference values for pregnant women in Tanzania.

Most HIV-seropositive women in this study were asymptomatic in the WHO clinical stage 1 . The distribution of T-lymphocyte subsets observed in this population was comparable to those reported in other studies involving asymptomatic HIV-seropositive pregnant women(26). CD4+ lymphocyte count of less than 200 cells $/ \mathrm{mm}^{3}$ is considered by the Centers for Diseases Control and Prevention (CDC) as an AIDS-defining laboratory criterion(30). Although a substantial proportion of HIVseropositive women in this study $(12.8 \%)$ met this laboratory criterion, most of these women were healthy and had no symptoms suggestive of AIDS. This suggests that laboratory parameters alone may not be adequate to define clinical stages of HIV disease among pregnant women in this population.
Although CD4+ lymphocyte count is the most used index of the level of cell mediated immunity in HIVinfected patients, it is not readily available in most developing countries. As a result, numerous simple and less expensive hematological indices are being considered as alternative measures of immunosuppression in HIVinfected people. For example, the cost of full blood count is about $21 \%$ of that of CD4+ lymphocyte count(4). Several studies have reported on the association between CD4+ lymphocyte count and other simple haematological indices $(4,5,8,9,10)$. Most of these studies have reported poor correlations in asymptomatic patients and much stronger associations in patients with advanced disease(4). In this study, we observed weak but significant correlations between haematological indices and CD4+ lymphocyte count in univariate analyses. In multivariate analyses, only total WBC count and ESR remained significant predictors of CD4+ lymphocyte count. However, WBC and ESR explained a very small proportion of the variance of CD4+ lymphocyte measurements, and had unacceptably low sensitivity and specificity even when the dichotomous cut-off point was optimised using an ROC curve. Hence, these simple haematological indices cannot be recommended for use as markers of cell mediated immunosuppression among asymptomatic women.

Women's age and mid-upper arm circumference (MUAC) were significant predictors of CD4+ lymphocyte count. The role of age as a predictor of CD4+ lymphocyte count among adults is uncertain. In normal healthy adults, an increase in CD4+ lymphocyte count with age has been reported by some studies $(31,32)$, while other studies have not observed any association(31). Similar conflicting results have been reported among HIV-seropositive populations(33). In this study, CD4+ lymphocyte count was inversely correlated with age among HIV-seropositive women. We also observed a weak but significant positive correlation between CD4+ lymphocyte count and MUAC. These associations might be confounded by duration of HIV-infection. Relatively high CD4+ lymphocyte count among younger women, with presumably more recent seroconversion, might be due to shorter duration of HIVinfection. Duration of infection has been shown to be a major predictor of CD4+ lymphocyte count and disease progression among HIV infected adults(34). Among HIVseronegative women, CD4+ lymphocyte count was not significantly correlated with age and anthropometric variables. This suggests that the observed associations between age and MUAC among HIV-seropositive women are related to HIV disease.

This study has several limitations. First, the power of this study to assess predictors of clinical stages of HIV disease was limited because most women were asymptomatic in WHO clinical stage 1 . Secondly, lack of information about the duration of infection limits our ability to adjust for this important predictor of CD4+ lymphocyte count in the analyses presented in this report. Hence, the observed association between CD4+ lymphocyte count and predictors might be confounded by duration of HIV disease. Thirdly, physiological changes 
associated with pregnancy were likely to have influenced the distribution of CD4+ lymphocyte count in this study. These changes might have affected some of the associations between potential predictors and CD4+ lymphocyte count.

In conclusion, HIV-seronegative women had significantly higher CD4+ lymphocytes count than HIVseropositive women. Most HIV-seropositive women were asymptomatic in WHO clinical stage 1 , but CD4+ counts were lower among women with stage 2 and 3 disease. Women's age and MUAC were significantly associated with CD4+ lymphocyte count among HIV-seropositive women. Results from simple haematological tests were weakly correlated with CD4+ lymphocyte count in both univariate and multivariate analysed. Hence, there were no simple haematological tests which could be recommended as alternative measures of HIV-related immunosuppression in this population of mainly asymptomatic women.

\section{ACKNOWLEDGEMENTS}

We are grateful to Dr. Ulla Larsen and Dr. Daniel Tarantola for their comments on the earlier drafts of this paper. We thank all women who agreed to participate in this study; investigators, research assistants, supervisors, laboratory technicians and administrative staff for all their efforts in the implementation of the study; and Muhimbili University College of Health Sciences for providing institutional support. This study was supported by the National Institute of Child Health and Human Development (NICHD R01 32257), the Fogarty International Center (NIH D43 TW00004), and Harvard School of Public Health. During the data analysis phase, Dr. Saidi H. Kapiga was supported by a training grant from the Fogarty International Center, National Institutes of Health (D43 TW00004) to the Harvard AIDS Institute.

\section{REFERENCES}

1. Gaubin M., Autiero M. and Houlgatte R., et al. Molecular basis of T lymphocyte CD4 antigen functions. Eur. J. Clin .Chem .Clin. Biochem. 1996; 34:723-728.

2. Fauci A.S. Multifactorial nature of human immunodeficiency virus disease: Implications for therapy. Science. 1993; 262:1011-1018.

3. UNAIDS/WHO working group on global HIV/AIDS and STD surveillance. AIDS epidemic update: December 1998, Geneva, Switzerland, December 1, 1998.

4. Beck E.J., Kupek E.J., Gompels M.M. and Pinching A.J. Correlation between total and CD4 lymphocyte counts in HIV infection: not making the good an enemy of the not so perfect. Int. J. STD AIDS. 1996; 7:422-428.

5. Schechter M., Zajdenverg R., Machado L.L., Pinto M.E., Lima L.A. and Perez M.A. Predicting CD4 counts in HIV-infected Brazilizna individuals: A model based on the World Health Organization staging system. J. AIDS. 1994; 7:163-168.

6. Montaner J.S.G., Le T.N., Le N., Craib K.J.P. and Schechter M.T Application of the World Health Organization system for HIV infection in a cohort of homosexual men in developing a prognostically meaningful staging system. AIDS. 1992; 6:719-724.

7. World Health Organization. Acquired immunodeficiency syndrome (AIDS): interim proposal for a WHO staging system for HIV infection and disease. Wkly Epidem. Rec. 1990; 65:221-224.

8. Lifson A.R., Allen S. and Wolf W., et al. Classification of HIV infection and disease in women from Rwanda. Evaluation of the World Health Organization HIV staging system and recommended modifications. Ann. Intern. Med. 1995; 122:262-270.

9. Lefrere J.J., Salmon D. and Doinel C. et al. Sedimentation rate as a predictive marker in HIV infection. AIDS. 1988; 2:63-64.

10. Schwartlander B., Bek B., Skarabis H., Koch J., Burkowitz J. and Koch M.A. Improvement of the predictive value of CD4+ lymphocyte count by beta 2-microglobulin, immunoglobulin A, and erythrocyte sedimentation rate. The Multicentre Cohort Study Group. AIDS. 1993; 7:813-821.

11. Moss A.R., Bacchetti P. and Osmond D. et al. Seropositivity for HIV and the development of AIDS or AIDS related condition: three year follow-up of the San Francisco General Hospital cohort. Brit. Med. J. 1988; 296:745-750.

12. Galai N., Park L.P., Wesch J., Visscher B., Riddler S. and Margolick J.B. Effect of smoking on the clinical progression of HIV-1 infection. J. AIDS. 1997; 14:45 1-458.

13. Burns D.N., Kramer A. and Yellin F. et al. Cigarette smoking: A modifier of Human Innubodeficiency Virus type 1 infection? $J$. AIDS. 1991; 4:76-83.

14. Baum M.K., Shor-Posner G. and Lu Y. et al. Micronutrients and HIV1 disease progression. AIDS. 1995; 9:1051-1056.

15. Tang A.M., Graham N.M.H., Kirby A.J., McCall L.D., Willet W.C. and Saah A.J. Dietary micronutrient intake and risk of progression to Acquired Immunodeficiency Syndrome (AIDS) in Human immunodeficiency virus type 1 (HIV-1) infected homosexual men. Amer. J. Epidem. 1993; 138:937-951.

16. Liang B., Chung S., Araghiniknam M., Lane L.C. and Watson R.R. Vitamins and immunomodulation in AIDS. Nutrition. 1996; 12:1-7.

17. United Republic of Tanzania, National AIDS Control Programme. HIV/AIDS/STD Surveillance Report, No. 12, December 1997, Dar es Salaam, Tanzania.

18. WHO Global Programme on AIDS. Proposed criteria for interpretation of results from Western blots assay for HIV-1, HIV-2 and HTLV-II. Wkly Epidem. Rec. 1995; 37:281-283.

19. Littell R.C., Milliken G.A., Stroup W.W. and Wolfinger R.D. SAS Systems for Mixed Models, Cary, NC: SAS Institute Inc., 1996.

20. Hankinson S.E., Manson J.E. and Spiegelman D. et al. Reproducibility of plasma hormone levels in post menopausal women over a 2-3 year period. Cancer Epidem. Biomarkers Prev. 1995; 4:649-654.

21. Rosner B. Fundamentals of Biostatistics, Duxbury Press, 1995.

22. Miller R.G. The jacknife - a review. Biometrika. 1974; 61:1-17.

23. Swets J.A. Measuring the accuracy of diagnostic systems. Science. 1988; 240:1285-1293.

24. Siridama V., Pacini F., Yang S.L., Moawad A., Reilly M. and de Groot L.J. Decreased levels of helper T cells: a possible cause of immunodeficiency in pregnancy. N. Engl. J. Med. 1982; 307:352-356.

25. Biggar R.J., Pahwa S. and Minkoff H. et al. Immunosuppression in pregnant women infected with human immunodeficiency virus. Amer. J. Obstet Gynecol. 1989; 161:1239-1244.

26. Miotti P.G., Liomba G., Dallabetta G.A., Hoover D.R., Chiphangwi J.D. and Saah A.J. T Iymphocyte subsets during and after pregnancy: analysis in HIV type 1 infected and uninfected Malawian mothers. $J$. Infect. Dis. 1992; 165:1116-1119.

27. Johnstone F.D., Thong K.J., Bird A.G. and Whitelaw J. Lymphocyte subpopulations in early human pregnancy. Obstet. Gynec. 1994; 83:941-946.

28. Siegel I. and Gleicher N. Changes in- peripheral mononuclear cells in pregnancy. Amer. J. Reprod. Immunol . 1981; 1:154-155.

29. Degenne D., Canepa S., Le Comte C., Renoux M. and Bardos P. Serial study of T-lymphocyte subsets in women during very early pregnancy. Clin. Immunol. Immunopathol. 1988; 48: 187-191.

30. Centers for Disease Control and Prevention. 1993 revised classification system for HIV infection and expanded surveillance case definition for AIDS among adolescents and adults. Morbid. Mortal. Wkly. Rec. 1992; 41:1-19.

31. Reichert T., DeBruyere M. and Deneys V. et al. Lymphocyte subset reference ranges in adult caucasians. Clin. immunol. Immunopathol. 1991; 60:190-208.

32. Parker J., Adelsberg B. and Azen S.P. et al. Leukocyte immunophenotyping by flow cytometry in a multisite study: Standardization, quality control, and normal values in the Transfusion safety study. Clin. immunol. Immunopathol. 1990; 55:187-220.

33. Lifson A.R., Rutherford G.W. and Jaffe H.W. The natural history of human immunodeficiency virus infection. J. Infect. Dis. 1988; 158:1360-1367.

34. Begtrup K., Melbye M., Biggar R.J., Goedert J.J., Knudsen K. and Andersen P.K. Progression to acquired immunodeficiency syndrome is influenced by CD4 T-lymphocyte count and time since seroconversion. Amer. J .Epidem. 1997; 145:629-635. 